\title{
Development of Improved Models for Estimation of Bursting Stresses in Elements under High-Concentrated Load
}

\author{
Brian Adjetey Boye ${ }^{\mathrm{a}} \mathbb{D}$ \\ Samuel Jonah Abbey ${ }^{b^{*}}$ (D)
}

Samson Ngambic (D)

Joao Fonte ${ }^{d}$ iD

a Principal Tunnel Engineer, Jacobs, Churchill way, Cardiff, United Kingdom. Email: fabiodebriyano@gmail.com

b Senior Lecturer in Geotechnical Engineering, Civil Engineering Division, Department of Geography and Environmental Management University of the West of England, Bristol, United Kingdom. Email: Samuel.abbey@uwe.ac.uk

c Senior Lecturer in Geotechnical Engineering, School of Energy, Construction and Environment, Coventry University, Coventry, United Kingdom. Email: apx290@coventry.ac.uk

d Tunnel Engineer, Jacobs, Elms House, Brook Green, London, United Kingdom. Email: joao_fonte_@hotmail.com

*Corresponding author

http://dx.doi.org/10.1590/1679-78255031

\begin{abstract}
In precast concrete segmental tunnels, radial and circumferential joints are often the most highly stressed parts and it is therefore important to use appropriate equations to accurately analysed these joints during design and provide adequate structural capacity to avoid failure. Different design codes have put forward equations for the estimation of bursting forces due to concentrated load on precast end blocks. The equations were specifically developed for pre-stressed concrete anchors and not specifically for precast concrete segmental tunnels. The design equations often account for the effects of load eccentricity in estimating bursting force but not the peak stress. This paper assesses the accuracy of published equations for bursting force and peak stress by conducting a high-resolution two-dimensional (2D) finite element (FE) based parametric studies. It was found that the effects of load eccentricity are significant for highly concentrated loads (load width ratios less than 0.3 ) and that they increase the peak bursting stresses significantly. Regression analysis is used to develop equations for estimating the peak bursting stress and bursting force due to load eccentricity for the design of precast concrete tunnel segments. These equations are more accurate as compared to pre-existing equations and important for practising engineers and designers.
\end{abstract}

\section{Keywords}

tensile bursting, precast concrete, tunnel segments, radial joint, circumferential joint.

\section{INTRODUCTION}

When a concentrated load acts on one of the joint faces of the segment, tensile bursting forces develop beneath the applied concentrated load. These tensile bursting forces are perpendicular to the applied load. The radial and circumferential joints of a tunnel segment are designed to prevent failure due to bursting. The radial joints are stressed due to the axial loads in the lining resulting from applied external ground or hydrostatic loads. The circumferential joints are stressed under the action of the Tunnel Boring Machine (TBM) thrust rams during construction. Figure 1.0 defines the $\mathrm{a} / \mathrm{d}$ ratios used to determine the magnitude of the bursting stress under the TBM thrust rams. 


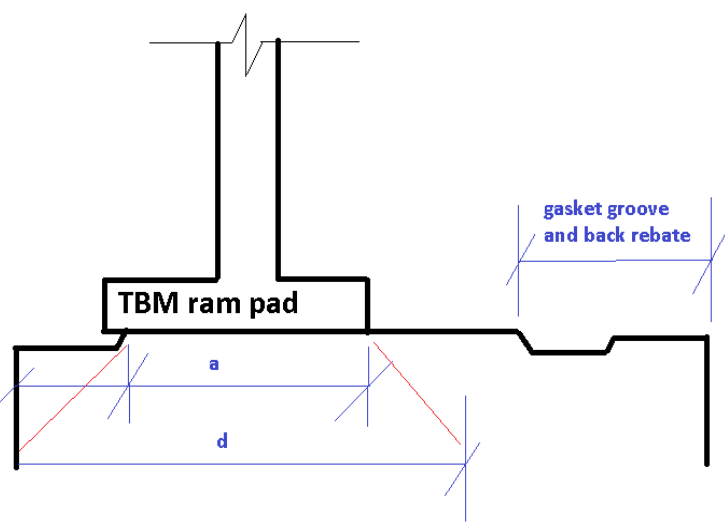

Figure 1 Definition of a and d dimensions for Tunnel Boring Machine Ram pad pushing against segment

The earliest work in literature to propose an equation for the bursting force was by Morsch (1922,1924). Further theoretical investigations are given in the literature by Bortsch (1935); Magnel (1949); Sievers (1952); Guyon (1953,1972); lyengar (1962); Yettram and Robbins (1969,1970); Sarles and Itani (1984). Of these the works by Guyon (1953,1972) and lyengar (1962) are the ones widely used in the present day industry in the design of precast segments. The theoretical solutions by Morsch $(1922,1924)$ can be derived using the strut and tie method (STM). The STM involves representing the flow of forces through the block with a truss and calculating the forces in the truss with one of the forces being the bursting force. It is an old conceptual tool that has been used for over a 100 years. For a concentrically loaded block, the STM solution is given as:

$\frac{T_{b}}{P}=\mathbf{0}_{.25}\left(\mathbf{1}-\frac{a}{d}\right)$

The accuracy of the various equations are assessed by comparison with a validated high resolution two-dimensional (2D) finite element analysis (FEA) model. The use of FEA provides near actual behaviour of materials such as concrete and cement-soil columns depending on loading condition (Abbey et al., 2015, 2016, 2017 and Olubanwo et al., 2017, 2018). The problem of a concentrated force at a precast tunnel segment joint can be idealised as a two-dimensional (2D) prismatic block as shown in Figure 2a. Where, a is the width of the applied load, $d$ is the depth of the prismatic block, e is the eccentricity of the applied load, $h$ is the height of the prismatic block and $P$ is the magnitude of the applied load. The distribution of the tensile stress is non-linear as shown in Figure $2 \mathrm{~b}$. This non-linear curve can be defined by the first position $\left(x_{0}\right)$ of zero tensile stress from the loaded area and the position $\left(x_{p}\right)$ of the peak stress (óp). The area under the bursting stress distribution is the total bursting force (Tb). The centroid of the bursting force occurs at a distance, $x_{c}$ from the loaded area. Values of bursting stress in this study are presented as proportions of the uniformly distributed basic stress, $\left(\sigma_{0}=\frac{P}{b d}\right)$ where $\mathrm{b}$ is the unit width of the two-dimensional prismatic block.

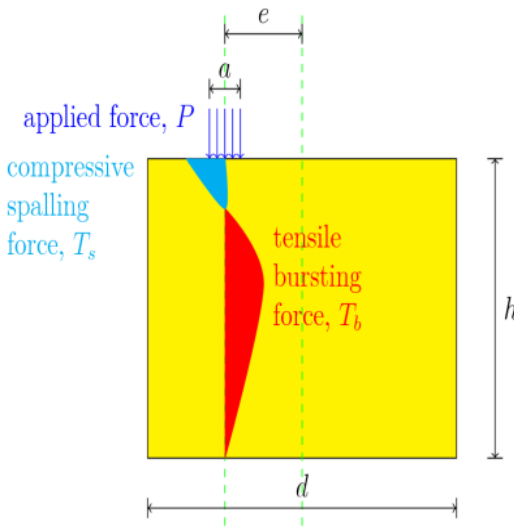

(a) Two-dimensional (2D) concentrated load on prismatic block

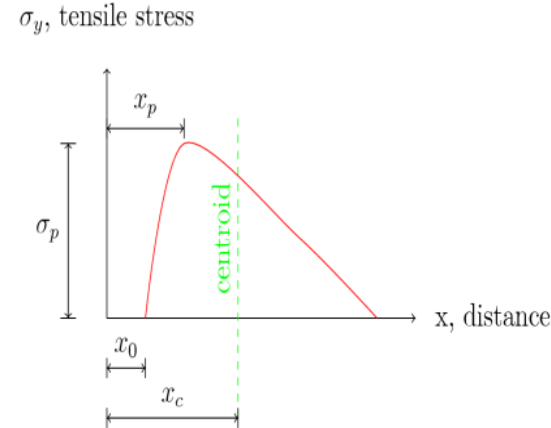

(b) Bursting stress distribution

Figure 2: Idealisation of precast segment joint 
Prismatic concrete and fibre reinforced concrete elements can experience two possible failure modes such as splitting tensile and concrete crushing failures under line and point loading (LL and PL) configurations. According to Conforti, et al., (2016) a LL configuration, characterized by a symmetrical axial load applied on a rectangular strip with loading strip width, a, (Figure 3a), induces to a two dimensional problem. While a PL configuration characterised by a concentrated load on a square area with side, a, (Figure 3b) leads to a three dimensional distribution of stresses. However, Square section is generally adopted for both LL and PL configuration (Schnütgen, 2003, Tiberti, et al., 2015 and Breitenbücher, et al., 2014).

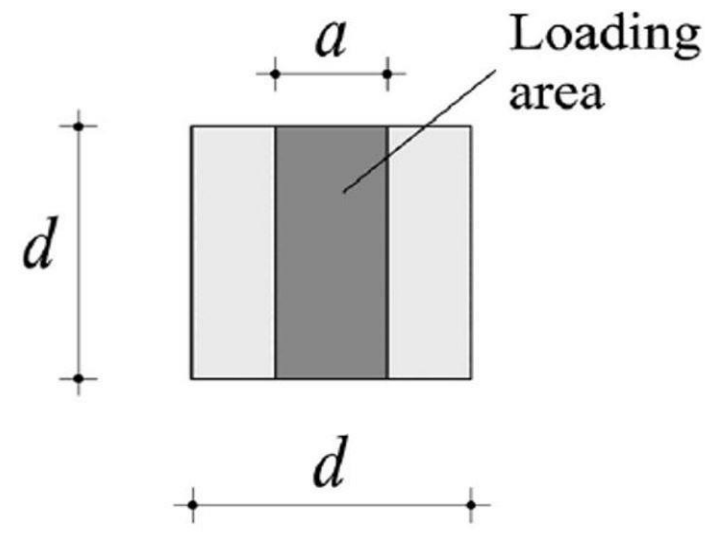

Figure 3a PL configuration

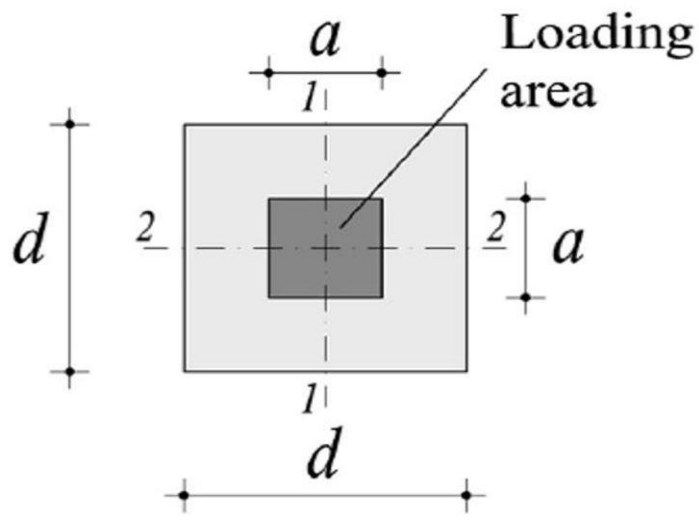

Figure 3b LL configuration (Conforti, et al., 2016)

Figure 3(a and b): Load configurations for studying local splitting behaviour of FRCS

The cracking for splitting varies with a/d ratio and loading configuration. For concrete element under line load, the cracking for splitting occurs in the a/d range from 0.17 to 0.83 , while in case of point load it occurs in a range from 0.25 to 0.91 however, crushing failure is predominant both at lower and higher values of a/d ratio. Concrete confinement can have a significant influence on the structural behaviour under a point load configuration due to lateral restraint. For concrete under point load, splitting crack occurs at concrete compressive stress level under the loading area significantly much higher than in case of line load. Study has shown that in a point load test the cracking for splitting occurs always at a value of the compressive stress under the loading area greater than the cylindrical compressive concrete strength due to confinement effect, (Conforti et al., 2016). In fibre reinforced element under a high concentrated load, the synthetic fibre provides a stable development of splitting cracks and increases load bearing capacity by providing crack-bridging forces against the applied load, (Schnütgen, 2003 and Tiberti, et al., 2015). Guyon $(1953,1972)$ investigated the tensile stresses responsible for cracking problems in early post- tensioning of precast concrete applications in Europe. Guyon's theory agreed with the results of a photo-elastic study by Tesar $(1932)$. Guyon $(1953,1972)$ proposed a symmetrical prism analogy for dealing with eccentric loads. In this analogy, an equivalent prism with dequivalent $=d-2 e$ is used to estimate the effects of eccentricity on the bursting stresses. Points of maximum and zero tensile stress were located by Guyon $(1953,1972)$ in his work. Iyengar $(1962)$ determined the stresses and tensile forces for the end of a pre- stressed beam, but the solution does not consider the effects of eccentricity. The solution by lyengar (1962) is presented in chart form for design. These charts have been reproduced in Figure $4 a$ and the parameters describing the bursting stresses have been fitted to equations in Figure $4 \mathrm{~b}$. This is to enable comparison of the study in this paper to the theoretical solution. 


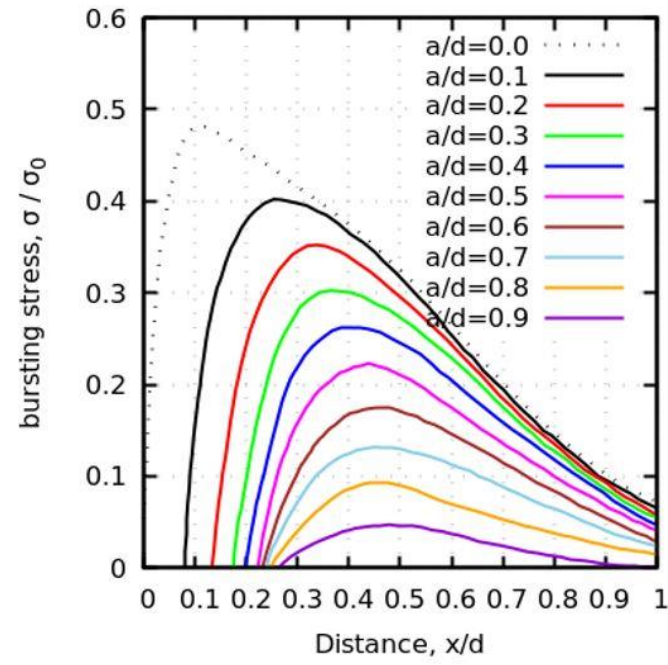

(a) Stress distribution
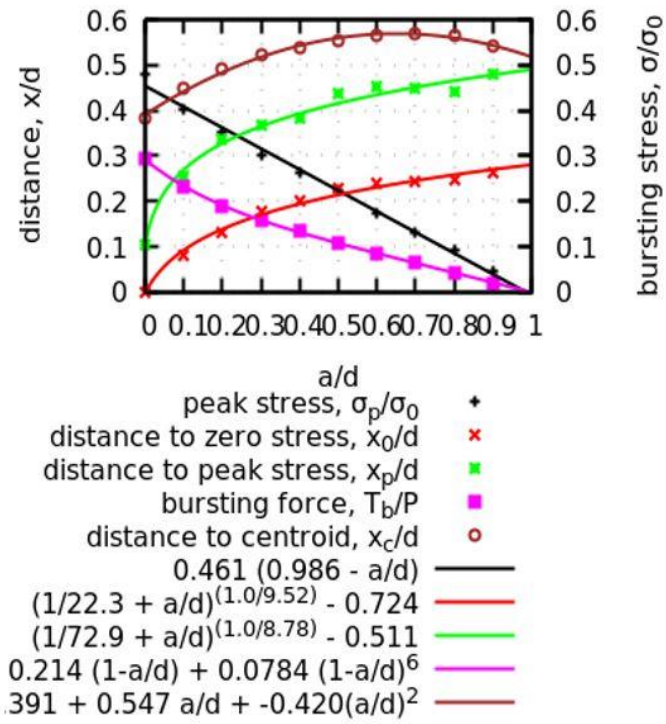

Figure 4: ( $a$ and b): Theoretical solution according to lyengar (Traced from Leonhardt (1964))

More recently, He and Liu (2011); Zhou et al. (2015) used polynomial equations defining the load transfer paths of force (isostatic lines of compression (ILC)) to derive equations for the bursting force and centroid of the force. Their equations for bursting force included the effects of eccentricity, however, the peak stress was not included in their study (Table 1). Di Carlo et al. (2016) presents a procedure for the design of precast tunnel segments for mechanical excavated tunnel lining in fibre reinforced concrete, without any traditional steel reinforcement. Tesar (1932) was among the earliest authors to investigate bursting forces using photo-elastic methods. The photo elastic method has been used by several authors including Christodoulides (1955,1957); Sargious (1960); Okada and Fujii (1964); Eimer et al. (1966). Eimer et al. (1966) included brass rods in their photo-elastic model to represent steel reinforcement. Sargious (1960) used the photo-elastic method for the determination of stresses and tensile forces in the anchorage zone of pre-stressed beams. Based on photo-elastic tests carried out by Sargious (1960), who was working in the same department as Leonhardt (1964), a formula (Equation 2) for the bursting force is given by the latter as:

$\frac{T_{b}}{P}=0.3\left(1-\frac{a}{d}(2)\right.$

Leonhardt (1964) proposed this linear relationship (Equation 2) because the theoretical solution by lyengar (1962) under-estimated the bursting force as compared to the experimental data from Sargious (1960). Leonhardt (1964) also summarised the previous publication by lyengar (1962), which was based on theoretical solutions, in a convenient form (charts) for reinforcement design. Morsch $(1922,1924)$ supported his work with tests carried out mainly on stone blocks with a few tests on plain and reinforced concrete specimens. Magnel (1949) compared his theoretical solution with two block tests, which showed that his solution under-estimated both the magnitude of tensile stresses and the distance to the point of maximum stress. Williams (1982) carried out a series of tests on the joints of reinforced tunnel segments. The failure modes were identified. The study concluded that the provision of transverse steel in the area of maximum tensile stress delays the onset of cracking and that treating the tunnel-lining segment as an end-block and designing it to the CP110 design code led to very conservative results. Ibell and Burgoyne (1992) carried out a series of tests on sixty specimens $(750 \mathrm{~mm} \times 250 \mathrm{~mm} \times 150 \mathrm{~mm})$ of strip-loaded pre-stressed reinforced concrete end blocks. The loads were placed centrally with a/d varying between 0.1 and 0.7. Ibell and Burgoyne (1992) concluded that the design methods used at the time in Europe were conservative and that it was beneficial to install steel reinforcement over greater depths than used in practice, thereby reducing the possibility of congestion. In the early 1990s, the University of Texas at Austin carried out dozens of model tests of anchorage zones (Burdet (1990); Zhou et al (2015), based upon which the design equations in the AASHTO (2014) and ACI318 (2014) were developed (Table 1). Moccichino et al. (2010) carried out flexural and point load tests on fibre reinforced concrete tunnel segments. These tests assessed the performance of fibre reinforced concrete as compared to steel reinforcement concrete and did not include assessment of the joint bursting 
capacity. Liao et al. (2015) conducted an experimental program using small scale specimens with and without fibre reinforcement. The experimental results were compared with analytical expressions based on a parabolic distribution of tensile stress. Yettram and Robbins $(1969,1970)$ used an elastic FE procedure for three-dimensional solids to assess the application of the design method of partitioning for multiple and eccentric anchorages on rectangular and I-section beams. However, they provided very little detail about the FE procedure. Yettram and Robbins $(1969,1970)$ found that Poisson ratio has little effect. Sarles and Itani (1984) used the FE method to model prestressed concrete girders for the evaluation of the usefulness of end blocks. The FE model was made up of eight node three-dimensional solid elements with three degrees of freedom per nodal point. Linear elastic, isotropic and homogeneous material properties were assumed. Sarles and Itani (1984) used a Poisson ratio of 0.167 (on the basis that Yettram and Robbins $(1969,1970)$ had shown that the Poisson ratio had little effect) and a Young's modulus for concrete of $28000 \mathrm{MPa}$. One of the conclusions of Sarles and Itani (1984), was that the maximum transverse tensile stresses increase with eccentricity. Burdet (1990) used elastic FE analysis in his study at the University of Texas in Austin to propose design equations which were later adopted in the American Standards. Hengprathanee (2004) carried out linear and non-linear FE analysis to derive equations for precast beams (rectangular, " $\mathrm{T}$ " and "I" shaped sections) considering the effects of a support reaction. A convergence test was carried out to confirm that the mesh size was appropriate. Load width ratios (a/d) of up to 0.5 and eccentricity ratios (e/d) of up to 0.4 were used in the study by Hengprathanee (2004). From the FE results, the bursting force $(\mathrm{Tb})$ was found to agree with Equation 1 for load width ratios $(\mathrm{a} / \mathrm{d})$ greater than 0.2 . However, for a knife edge load $(\mathrm{a} / \mathrm{d}=0)$, the bursting force was found to be about (0.42P), which is much higher than 0.3P according to Leonhardt (1964). Hengprathanee (2004) proposed a modified equation ( $x c=0.5+0.25 \mathrm{a} / \mathrm{d})$ for the position of the peak stress. However, the magnitude of the peak stress was not compared with the FE results in the study. Gupta and Khapre (2008) used a FE computer code on the platform of a supercomputer known as "PARAM 10000" in their study. The effect of Poisson's ratio over the bursting tensile force is studied and an equation for the bursting force incorporating the effect of the Poisson ratio is proposed. A discretized mesh consisting of 4800 triangular elements with 2501 nodes is used in their study. Gupta and Khapre (2008) showed that the peak bursting stress increases with eccentricity but did not include the effects of eccentricity in their proposed equation. Francis and Mangione (2012) verify the design charts by Leonhardt (1964) using a numerical analysis for a concentrically applied load. In their study, the effect of the contact stress distribution at the joint of a precast tunnel segment on bursting is highlighted and a procedure for the design of steel fibre reinforced concrete (SFRC) tunnel segments involving the use of non-linear numerical analysis is proposed. The British Standard (BS), BS8110 (1997), gives a table of values (Tb/P ratios) for estimating the total bursting force (Tb). The values from this table have been presented as an equation in this paper for comparison (See Table 1.0). The Eurocode (2004) provides equations (See Table 1.0) for estimating the bursting force (Tb). The equations in the Eurocode (2004) take the effects of the height-to-width ( $h / d$ ) in account. The German Tunnelling Committee (DAUB) (2013) gives equations for estimating the bursting force and with an equation for the additional bursting force due to large eccentricities (e >d/6). The American Standard, ACI318 (2014) gives equations (See Table 1.0) for both the magnitude of the bursting force $(\mathrm{Tb})$ and the centroid $(\mathrm{xc}$ ) of the bursting force. The ACl318 (2014) clarifies that the equation for the bursting force is only applicable to small eccentricities and therefore confirms that limitation of the equation.

Table 1: Comparison of published equations from literature

\begin{tabular}{|c|c|c|c|}
\hline & Bursting force, $T_{b}$ & Peak Stress, óp & Centroid. $\mathbf{x}_{\mathbf{c}}$ \\
\hline Guyon $(1953,1972)$ & $1.1 \times 0.25\left(1-\frac{a}{d}\right) P$ & $1.1 \times 0.47\left(1-\frac{a}{d}\right) \frac{P}{a b}$ & - \\
\hline Leonhardt (1964) & $0.3\left(1-\frac{a}{d}\right) P$ & - & - \\
\hline BS8110 (1997) & $\left(0.32-0.3 \frac{a}{d}\right) P$ & - & - \\
\hline Eurocode (2004) & $\begin{array}{c}\mathrm{h} / \mathrm{d}>=2,0.25\left(1-\frac{a}{d}\right) P \\
\mathrm{~h} / \mathrm{d}<2,0.25\left(1-0.7 \frac{a}{h}\right) P\end{array}$ & - & - \\
\hline Gupta and Khapre (2008) & $\left(0.239-0.267 \frac{a}{d}+0.075 v\right) P$ & - & - \\
\hline He and Liu (2011) & $0.22\left(1+\frac{2 e}{d}\right)^{2}\left(1-\frac{2 e}{d}-\frac{a}{d}\right) \sum P$ & - & - \\
\hline DAUB (2013) & $0.25\left(1-\frac{a}{d}\right) P$ & - & - \\
\hline
\end{tabular}




\begin{tabular}{|c|c|c|c|}
\hline & Bursting force, $T_{b}$ & Peak Stress, óp & Centroid. $\mathbf{x}_{\mathrm{c}}$ \\
\hline $\mathrm{ACl} 318(2014)$ & $0.25\left(1-\frac{a}{d}\right) P$ & - & $0.5(d-2 e)$ \\
\hline AASHTO (2014) & $0.25\left(1-\frac{a}{d}\right) \sum P$ & - & $0.5(d-2 e)$ \\
\hline Zhou et al (2015) & $0.25\left(1+\frac{2 e}{d}\right)^{2}\left(1-\frac{2 e}{d}-\frac{a}{d}\right) \sum P$ & - & - \\
\hline
\end{tabular}

\section{Finite Element Analysis}

Most literatures provided equations for bursting force (Tb) with fewer giving further equations for other parameters describing the bursting stress distribution as highlighted in the earlier section. Most of the equations do not consider the effects of eccentricity. According to Stone and Breen (1981), in dealing with complex geometries where the stress field may change rapidly, two approaches can be employed to achieve accurate solution. These are either mesh refinement or the use of high order elements. Therefore, in this paper a high resolution mesh has been used together with second order elements (Quadratic plane-strain elements with 8 No nodes each). The amount of time required to build numerical models means that closed form solutions are more suitable during design for simple problems. A high resolution linear elastic FE model is used in this study, to confirm the theoretical solutions provided in previous studies and develop closed form solutions to account for the eccentricity of the load. An automatic mesh generator is used in this study to create several rectangular meshes of varying grid size to test the convergence of the model results. A model was set up using typical parameters of precast concrete segments for tunnel linings. A block depth (d) of $300 \mathrm{~mm}$ was chosen for this study as many segmental linings are close to $300 \mathrm{~mm}$ thick, (Boye et al., 2018). Typical values for the elastic modulus ( $\mathrm{Ec}=36400$ $\mathrm{MPa}$ ) of concrete (45MPa cylinder strength), Poisson ratio ( $\mathrm{vc}=0.2)$ and concentrated load $(P=3000 \mathrm{kN} / \mathrm{m}$ ) were used in this study. Later in this paper, it is shown that the results are not sensitive to the elastic modulus and the magnitude of the concentrated load. The block height $\mathrm{h}$ was assumed to be equal to the block depth. The block depth (d) was divided into 200 elements in each dimension to give a mesh size of $1.5 \mathrm{~mm} \times 1.5 \mathrm{~mm}$ (grid dimension of $200 \times 200$ ), leading to a model made up of 120801 No nodes and 40000 No elements. The use of such a fine mesh as shown in Figure 5 meant that results of the analysis were not highly sensitive to the mesh size. The FE model was set up with 20 No different load widths (a) ranging from $15 \mathrm{~mm}(0.05 \mathrm{~d})$ to $285 \mathrm{~mm}(0.95 \mathrm{~d})$ in increments of $15 \mathrm{~mm}(0.05 \mathrm{~d})$ and $17 \mathrm{No}$ load eccentricities (e) ranging from zero to $120 \mathrm{~mm}(0.4 \mathrm{~d})$ in increments of $7.5 \mathrm{~mm}(0.025 \mathrm{~d})$. In combinations of load width (a) and eccentricity (e) where the whole load width was not within the block $(e+0.5 a>0.5 d)$, the combination was discarded. This lead to a total of 187 No of different load combinations analysed in this study.

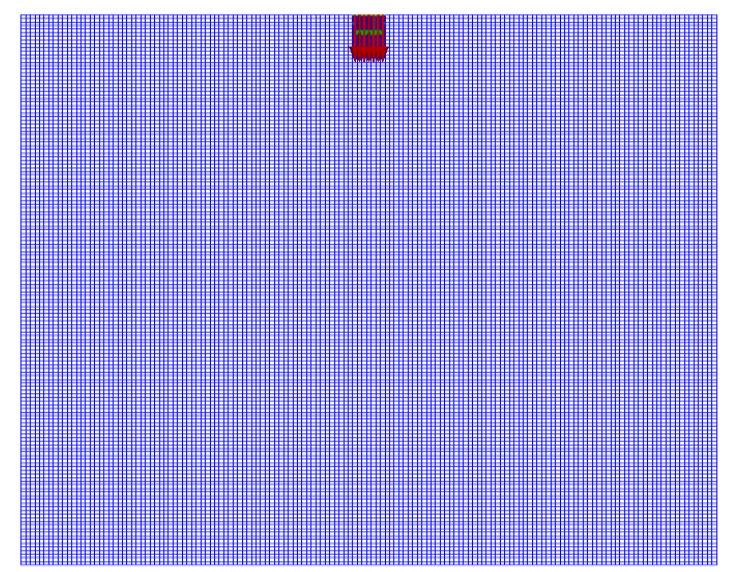

Figure 5: Typical high resolution mesh used in analysis

\section{Results and Discussion}

\subsection{Effect of a/d ratio}

In this study, the transverse tensile stresses are estimated for varying load width ratios $(\mathrm{a} / \mathrm{d})$ using an FE model. The eccentricity is set at zero for the initial assessment on the effects of the load width ratio. Comparison of the theoretical equations by lyengar $(1962)$ and Guyon $(1953,1972)$ with the FE results in this study show that this study agrees well 
(See Figure 6) with the theoretical solution by lyengar (1962). However, the equation by Guyon (1953, 1972) for the peak stress are significantly conservative (Figure $6 b$ ) for small load width ratios (a/d).

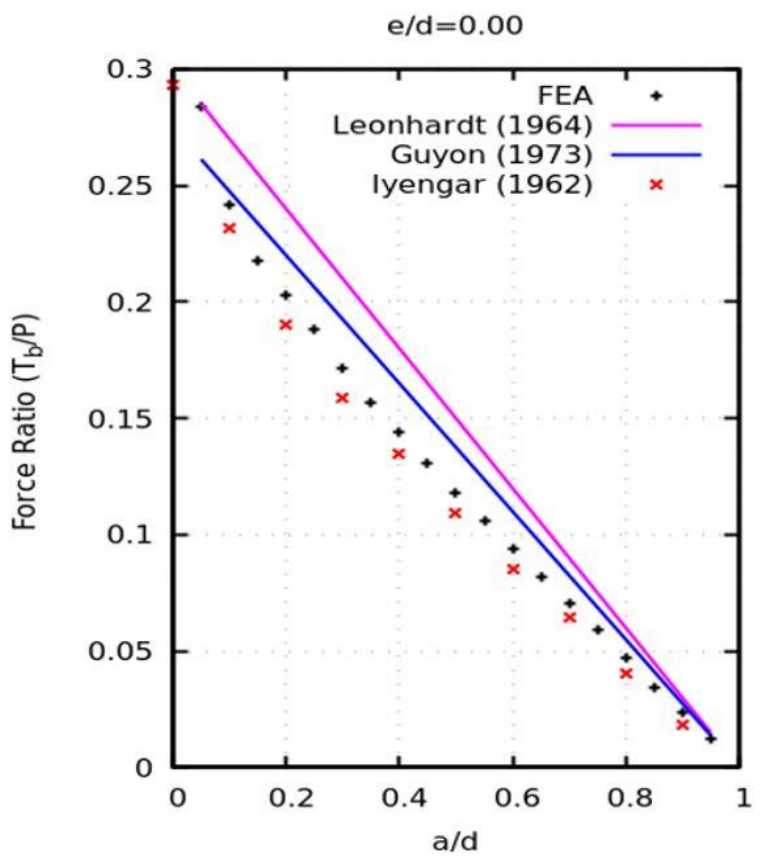

(a) Bursting force

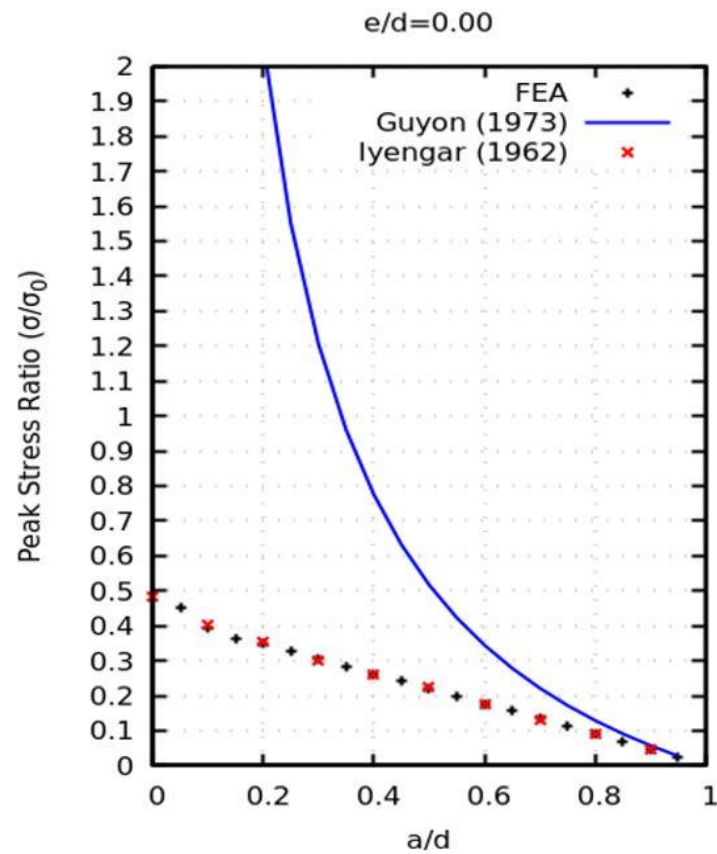

(b) Peak stress

Figure 6( $a$ and b): Comparison of theoretical solutions with FEA

A comparison of various design standards with the FE analysis for a concentrically loaded block and the distribution of bursting stresses are shown in Figure 7 and 8 respectively.

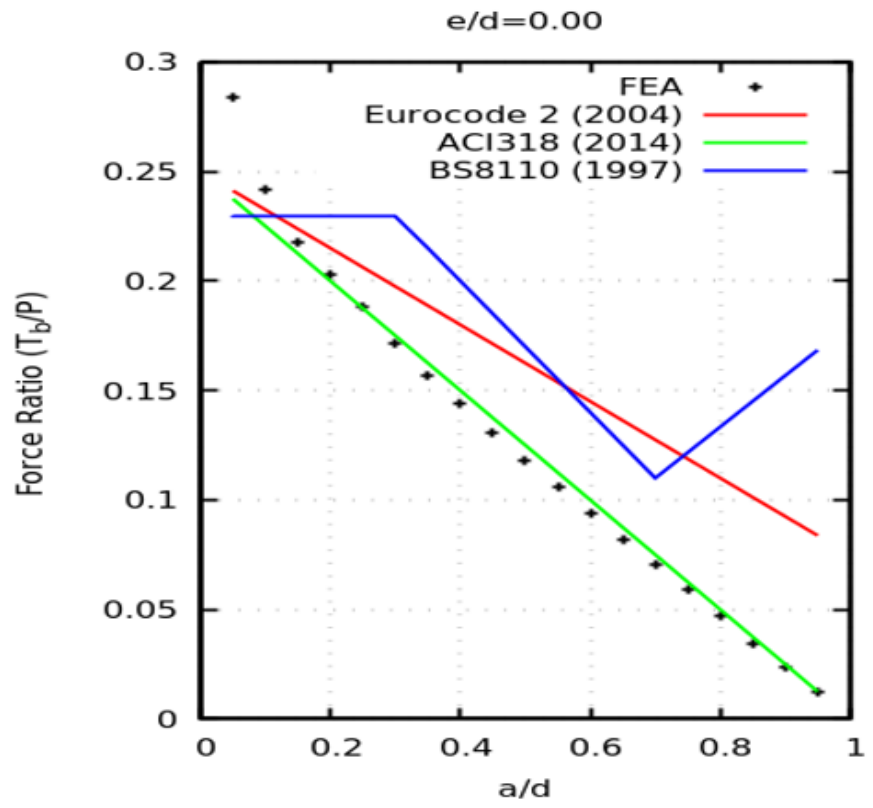

Figure 7: Comparison of bursting forces for design codes and FEA 


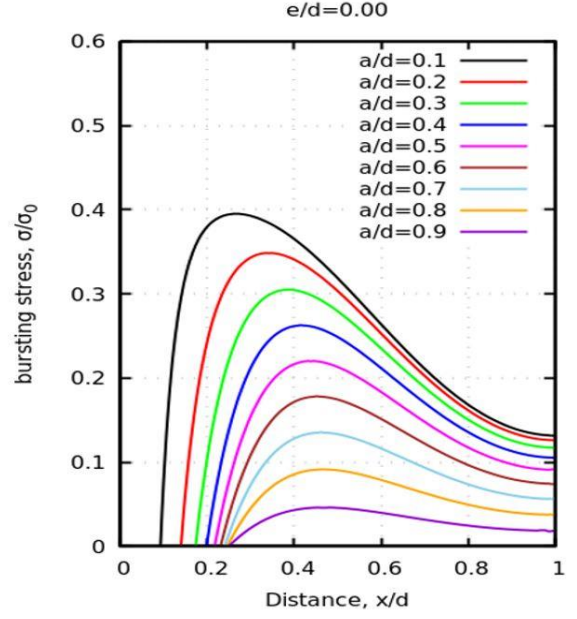

(a) Stress distribution

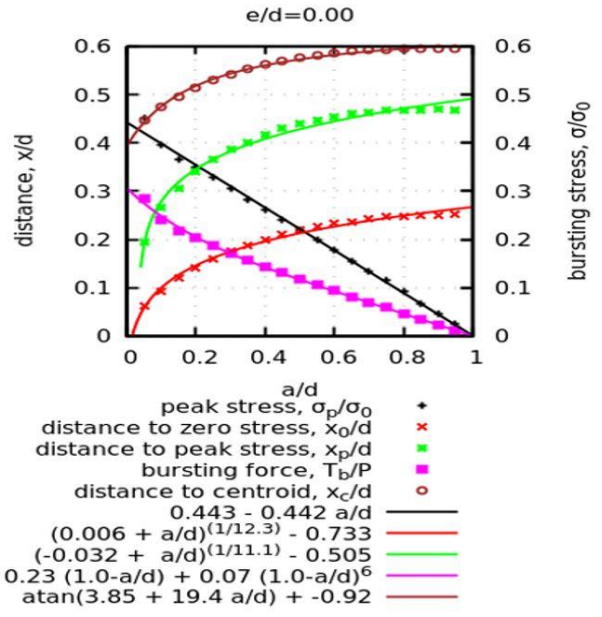

(b) Summary of parameters

Figure 8.0( $a$ and b): Distribution of bursting stress according to FE analysis

However, higher peak stresses and bursting forces are obtained when $a / d=0.05$. These higher values suggest Equation 1 which is also adopted in most of the design standards (ACI318, 2014; AASHTO, 2014) is not suitable for load width ratios (a/d) less than 0.2. The applied load was changed from $3000 \mathrm{kN}$ to $1000 \mathrm{kN}$ for a load width ratio (a/d) of 0.05, however there was no change (for up to 12 decimal places) in the total bursting force ratio. Similarly, the elastic modulus was reduced from $36400 \mathrm{MPa}$ to $10000 \mathrm{MPa}$ and found to have no effect on the bursting force ratio. The sensitivity to the Poisson's ratio (í) was assessed by changing the Poisson ratio from 0.2 to 0.1 which led to a decrease in the bursting force ratio from 0.2857 to 0.2855 . Further reducing the Poisson ratio to zero changed the bursting force ratio to 0.2853 . This showed that as the Poisson ratio increases, the bursting force increases confirming the trend observed by Gupta and Khapre (2008). However, the effect of the Poisson ratio was too small (less than $0.1 \%$ ) to be significant for design. A convergence test was carried out by varying the mesh size (See Figure 9). It was observed that the results had converged very well for load width ratios $(a / d)$ greater than 0.1 . For the load width ratio of 0.1 , there was a variation of about $5 \%$ in the bursting force and peak stress at a grid dimension of $200 \times 200$. However, for a load width ratio $(\mathrm{a} / \mathrm{d})$ of 0.05 , the variation was around $17 \%$. A grid dimension of $200 \times 200$ was chosen for the regression analysis in this study since this gave values mid-way between the upper bound and lower bound values in Figure 9 . The convergence test also confirmed that a high-resolution mesh is very important when modelling small load width ratios (a/d). 


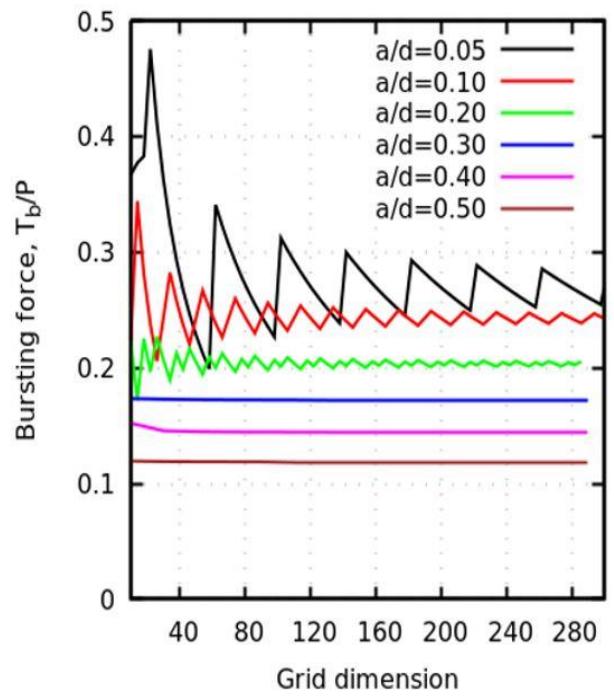

(a) Bursting force

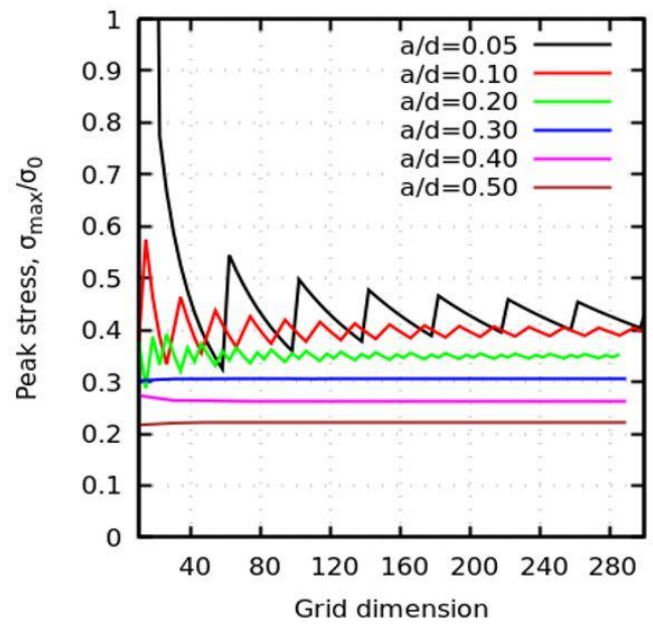

(b) Peak stress force

Figure 9: Convergence of FEA model

\subsection{Effects of Eccentricity (e/d) on Bursting Force}

It was observed that as the eccentricity increases the bursting force reduces (Figure 10a). The rate of the reduction is higher at larger eccentricities (Figure 10b). The reduction of bursting force with increasing eccentricity can be incorporated in design using the equivalent prism method suggested by Guyon $(1953,1972)$ or the equation by Leonhardt (1964) with dequivalent $=d-2$ e (equivalent prism). As shown in Figure 11 for a load width ratio of 0.15, the Guyon (1953, 1972) equation is just above the FEA results whilst the solution by Leonhardt (1964) is higher up. Both methods seem to provide a good enough value of bursting force for design even though there is some under estimation at very high eccentricity ratios (around 0.4 ). Eccentricity ratios (e/d) of around 0.4 do not typically occur in precast segment design, so the discrepancy is unlikely to be of relevance to segmental lining design. The more recent equations by He and Liu (2011); Zhou et al. (2015) even though closer to the FE results, under-estimates the bursting force at high eccentricities.

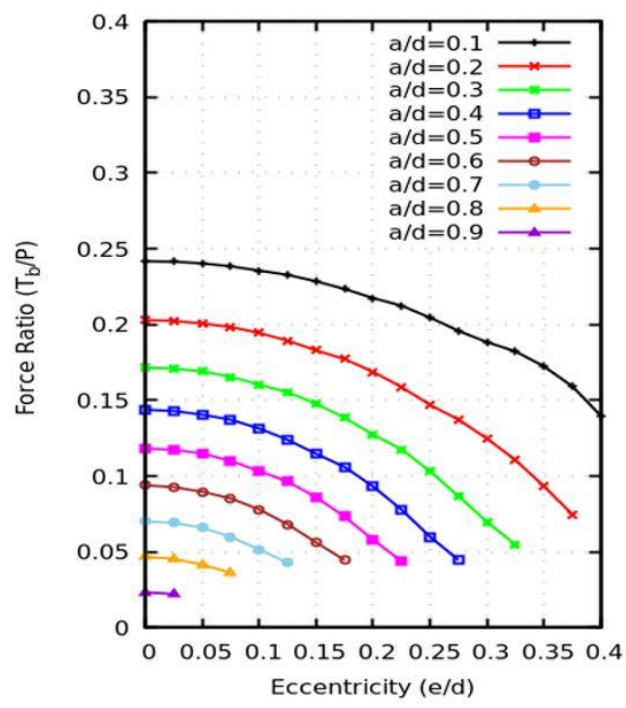

(a) Bursting force versus eccentricity

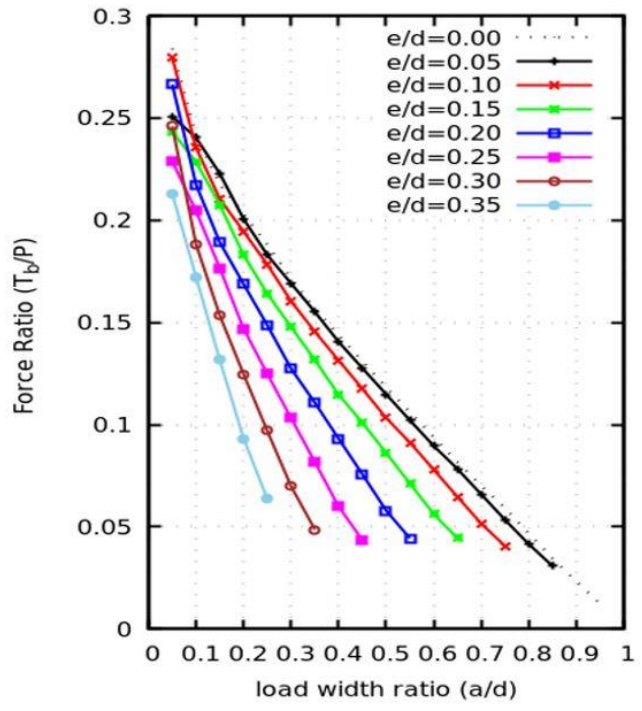

(b) Bursting force versus load width

Figure 10: ( $a$ and $b)$ : Effects of eccentricity on bursting force (FEA results) 


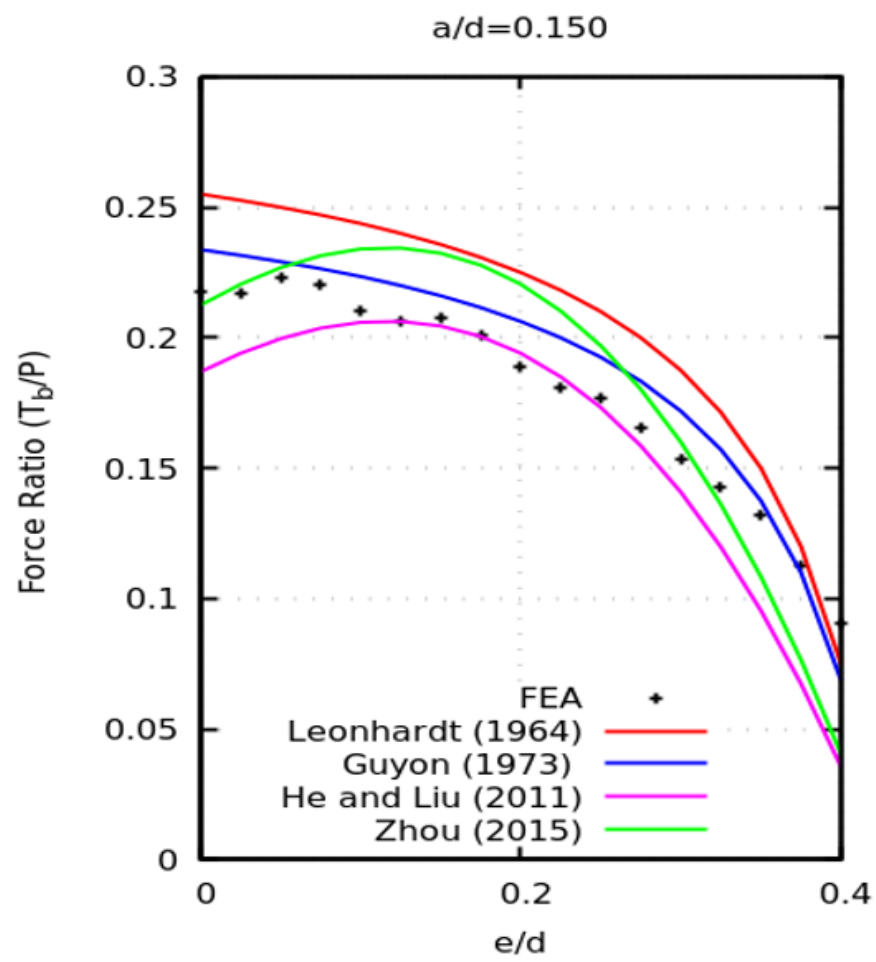

Figure 11: Effect of eccentricity on bursting for $a / d=0.15$

\subsection{Effects of Eccentricity (e/d) on Peak Stress}

From the FEA results, it was observed that for load width ratios greater than 0.3 , the peak stress reduces as the eccentricity increases (Figure 12). The amount of reinforcement required reduces with eccentricity, because the bursting force reduces while the peak stress increases. However, for fibre reinforced concrete segments, more fibres may be required to increase the flexural tensile strength. The increase in peak stress with eccentricity for low load width ratios, has also been confirmed by Sarles and Itani (1984); Gupta and Khapre (2008). However, for load width ratios (a/d) less than 0.3 , the peak stresses increase as shown in Figure 12a and Figure 13 respectively. Figure 14 shows that the Guyon method is very conservative for peak stress whilst the use of the theoretical solution by lyengar (1962) with the equivalent prism method under-estimates the peak stress for low load width ratios (less than 0.3). 


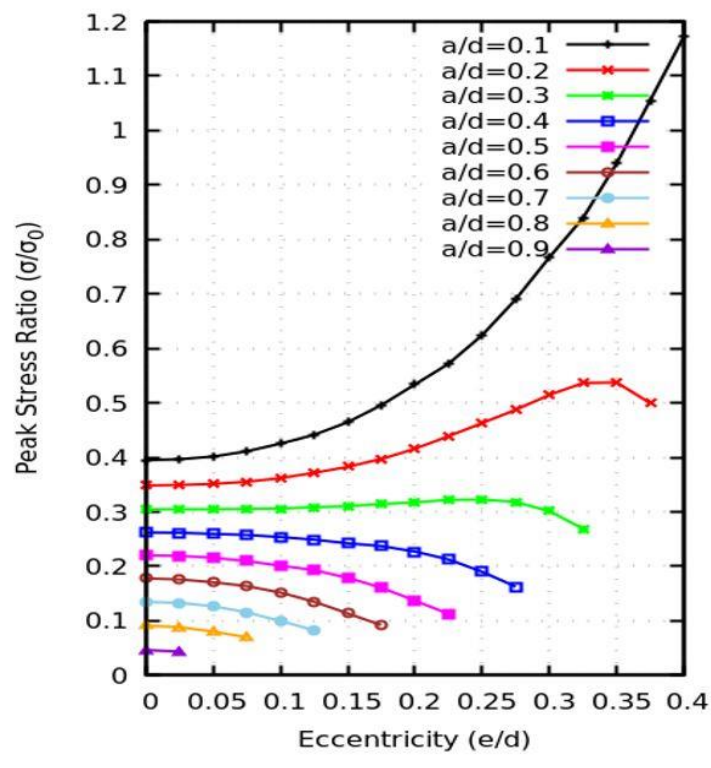

(a) Peak stress versus eccentricity

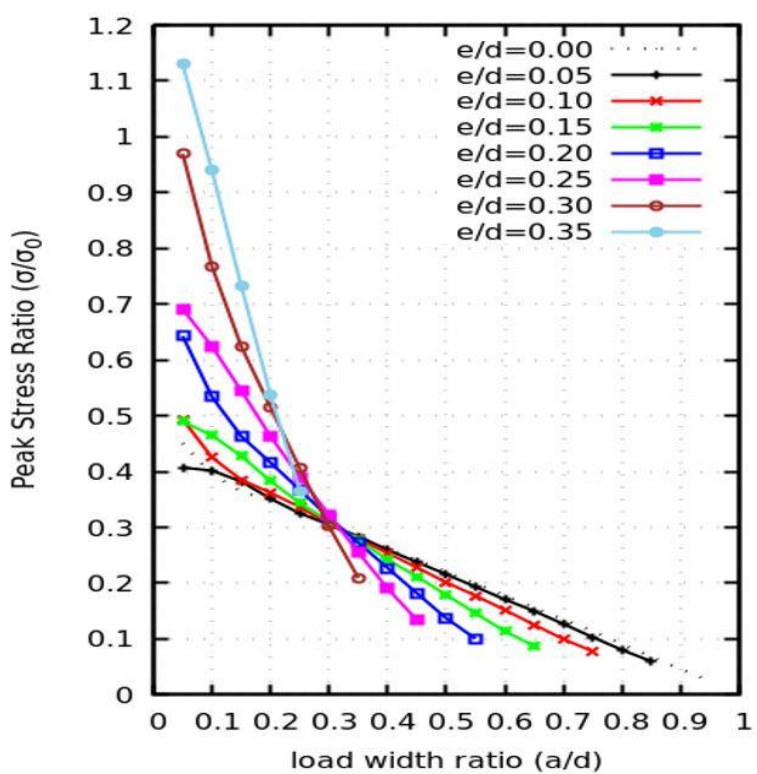

(b) Peak stress versus load width

Figure 12.0: Effects of eccentricity on peak stress (FE results)

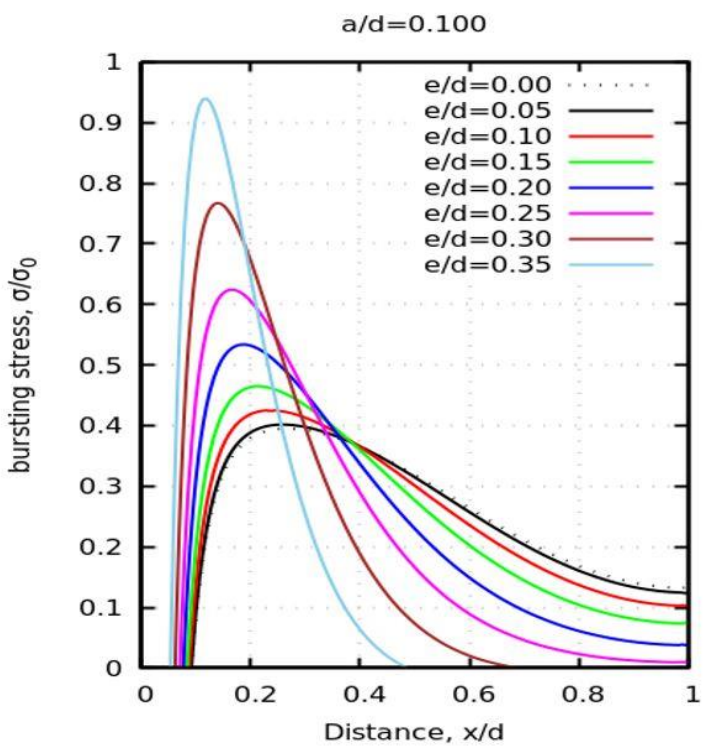

(a) Load width ratio, $(\mathrm{a} / \mathrm{d}=0.1)$.

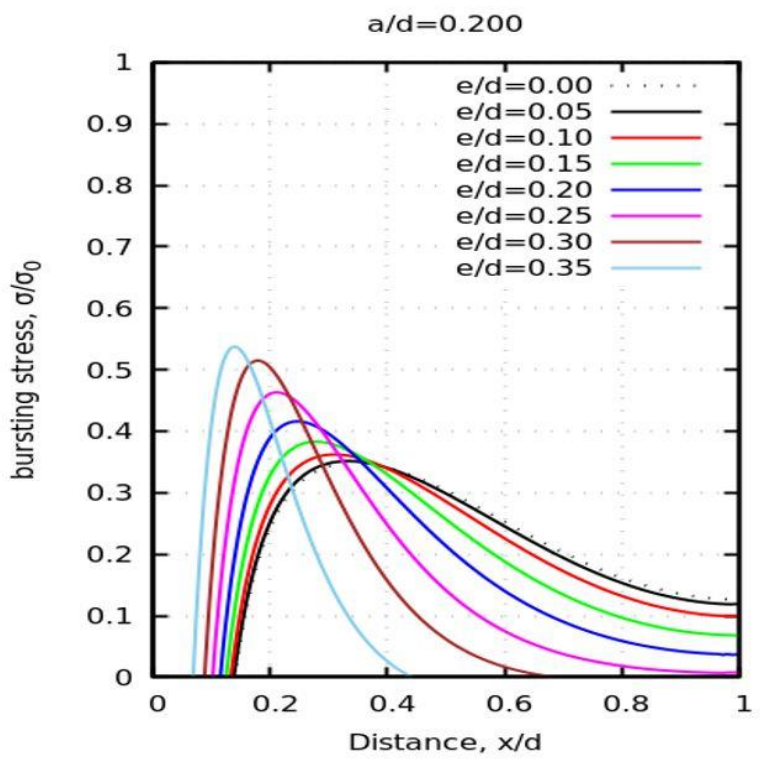

(b) Load width ratio, $(\mathrm{a} / \mathrm{d}=0.2)$

Figure 13.0( $a$ and $b$ ): Effects of eccentricity 


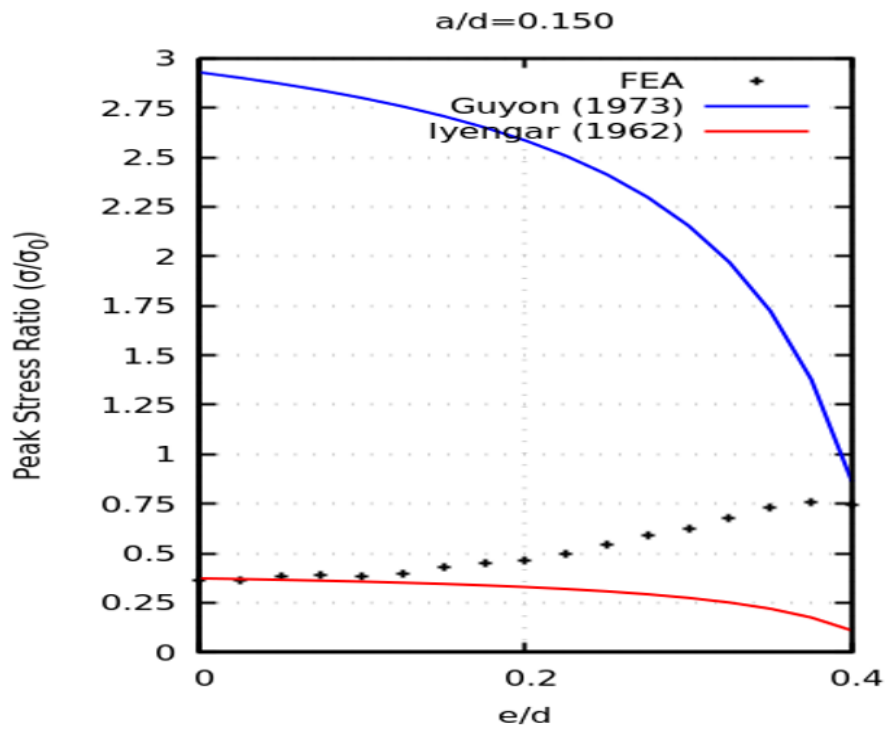

Figure 14: Effect of eccentricity on peak stress for $a / d=0.15$

The load width ratios for the most onerous scenarios at the radial joint in precast segment design range from about 0.1 to 0.3 , hence this increase in peak stress with increasing eccentricity is important for design.

\subsection{Proposed Bursting Force and Peak Stress Equations}

The results of the FE analysis in this study agree with the theoretical solution given by lyengar (1962) for a symmetrically loaded arrangement. However, the theoretical solution does not account for the effects of eccentricity. The FE analysis has also confirmed the effects of eccentricity on the bursting force and peak stress. Most published equations for the bursting force $(T b=0.25 P(1-a / d))$ agree with the theoretical and FE solution when $a / d$ is greater than 0.2 , however, the non-linearity which occurs when $\mathrm{a} / \mathrm{d}$ is less than 0.2 is not accounted for. Using regression analysis in this study to account for the non-linearity which occurs when a/d is less than 0.2 and the effects of eccentricity in reducing the bursting force gives the proposed equation for bursting force (Equation 3). The mean absolute difference between the FEA results and the proposed equation was found to be $\boldsymbol{T}_{\boldsymbol{b}} / \boldsymbol{P}=\mathbf{0 . 0 0 2 7}$ which is about $1 \%$ of the maximum bursting force for a knife edge $(a / d)$ load. There is a lack of equations for the peak bursting stress in the design codes. However, it is known from published papers and proven in this study that the peak bursting stress is linearly proportional to the load width ratio $(\mathrm{a} / \mathrm{d})$ and that the peak stress increases with eccentricity (for load width ratios less than 0.3 ). Further investigation of the FEA results (Figure 12b) showed that the relationship between the peak stress (óp) and a/d remained close to linear at different eccentricities. However, there is a non-linear increase in the slope of the line with increasing eccentricity and the intercept of the lines reduces with increasing eccentricity. The relationship between peak stress and load width ratio (a/d) can be described by Equation 4, where the intercept and gradient terms vary with eccentricity as shown in Table 2.

$$
\begin{aligned}
& \frac{T_{b}}{P}=0_{.235}\left(1.0-\frac{a}{d}\right)+0_{.061}\left(1.0-\frac{a}{d}\right)^{6}-\left(0.65 \frac{a}{d}+0.094\right)\left(\frac{2 e}{d}\right)^{2}(3) \\
& \frac{\sigma_{p}}{\sigma_{0}}=\left[\mathbf{0}_{.453}+2.89\left(\frac{2 e}{d}\right)^{3} .136\right]-\left[0_{.440}+\frac{1}{30.4} \exp \left(6.83 \frac{2 e}{d}\right)\right] \frac{a}{d} \\
& \text { Intercept }
\end{aligned}
$$

Table 2: Variation of equation coefficients with eccentricity

\begin{tabular}{ccc}
\hline e/d & Intercept & Gradient \\
\hline 0.000 & 0.436 & 0.433 \\
0.025 & 0.438 & 0.438 \\
0.050 & 0.444 & 0.455 \\
0.075 & 0.455 & 0.487 \\
0.100 & 0.472 & 0.536
\end{tabular}




\begin{tabular}{llc}
\hline e/d & Intercept & Gradient \\
\hline 0.125 & 0.496 & 0.604 \\
0.150 & 0.529 & 0.699 \\
0.175 & 0.573 & 0.827 \\
0.200 & 0.634 & 1.006 \\
0.225 & 0.729 & 1.298 \\
0.250 & 0.815 & 1.598 \\
0.275 & 0.886 & 1.879 \\
0.300 & 1.002 & 2.357 \\
0.325 & 1.160 & 3.079 \\
0.350 & 1.368 & 4.167 \\
0.375 & 1.679 & 6.078
\end{tabular}

Table 2.0 shows the intercept and gradient terms for different eccentricities obtained from the regression analysis. The mean absolute difference between the FEA results for peak stress and the proposed equation was found to be $=$ 0.017 which is about $\mathbf{3} \%$ of the maximum peak stress for a knife edge $(a / d)$ load.

\section{Conclusions}

The equation commonly used for bursting force (Equation 1) has been improved by accounting for the non-linearity at low load width ratios $(\mathrm{a} / \mathrm{d})$ and including the effects of eccentricity. The proposed equation (Equation 3 ) agrees with both theoretical and numerical elastic solutions. The equivalent prism method is good for predicting the bursting force due to eccentricity but not for the peak stress for highly concentrated loads (load width ratios less than 0.3 ). Therefore, using the equivalent prism method to predict the peak stress due to eccentricity can lead to under-estimation. The linear relationship between $\mathrm{a} / \mathrm{d}$ and peak stress is maintained at different eccentricities but the slope and intercept change significantly. The proposed equation (Equation 4) for the peak stress can enable more efficient design. It was also confirmed in this study that a high resolution mesh is very important when using the finite element method to model small load width ratios.

\section{List of abbreviations:}

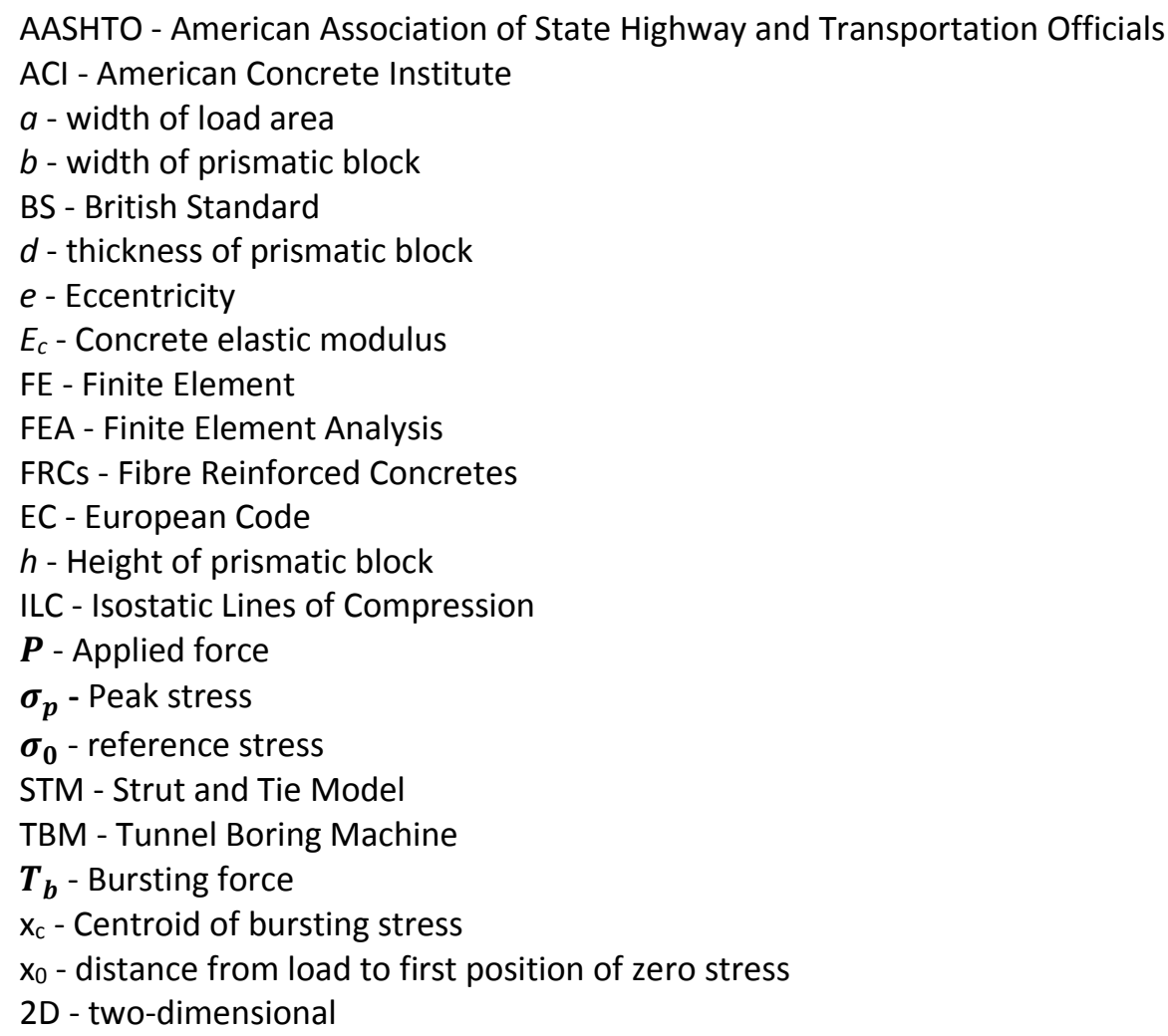




\section{References}

Abbey, S.J., Ngambi, S., Coakley, E. (2016) Effect of Cement and by-product material inclusion on plasticity of deep mixing improved soils, International Journal of Civil Engineering and Technology, 7 (5), pp. 265-274.

Abbey, S.J., Ngambi, S., Olubanwo, A.O. (2017) Effect of overlap distance and chord angle on performance of overlapping soilcement columns, International Journal of Civil Engineering and Technology, 8 (5), pp. 627-637.

Abbey, S.J., Ngambi, S., Ngekpe, B.E. (2015) Understanding the performance of deep mixing improved soils - A Review, International Journal of Civil Engineering and Technology, 6 (3), pp. 97-117.

Association of State Highway and Transportation Officials (2014) AASHTO, AASHTO LRFD Bridge Design Specifications. Washington D.C., Association of State Highway and Transportation Officials (AASHTO). 7th Edition.

American Concrete Institute (2014) ACl318, Building Code Requirements for Structural Concrete (ACI 318M-14) and Commentary ( $\mathrm{ACl} 318 \mathrm{RM}-14)$. Michigan, American Concrete Institute ( $\mathrm{ACl})$

Boye, B.A., Abbey, S.J., Olubanwo, A.O. and Fonte, J. (2018) Non-Linear Analysis of Precast Concrete Segment Joints under High Compressive Loads, International Journal of Applied Engineering Research Volume 13, Number 9 (2018) pp. 6979-6988.

Bortsch, R. (1935) Die Spannungen in Wa1zge1enkquadern. Beton und Eisen, 35(4), 61 - 66.

Breitenbücher R, Meschke G, Song F, Hofmann M, Zhan Y. Experimental and numerical study on the load-bearing behaviour of steel fiber reinforced concrete for precast tunnel lining segments under concentrated loads. FRC 2014 Joint ACl-fib International Workshop, Montreal, Canada, 24-25 July 2014, pp. 417-429.

British Standards Institute. (1997) BS8110, Structural use of concrete - Part 1: Code of practice for design and construction. Standard, British Standards Institute (BSI)

British Standards Institute. (2004) Eurocode 2: design of concrete structures - Part 1-1: General rules and rules for buildings Incorporating corrigenda January 2008, November 2010 and January 2014, London, British Standard Institution

Burdet, O. L., Analysis and Design of Anchorage Zones in Post-Tensioned Concrete Bridges. Phd thesis, The University of Texas at Austin, 1990.

Conforti, A., Tiberti, G. and Plizzari, G.A. (2016), Splitting and crushing failure in FRC elements subjected to a high concentrated load, Composites Part B, 105, pp. 82-92.

Di Carlo, F., Meda, A., \& Rinaldi, Z. (2016) Design procedure for precast fibre-reinforced concrete segments in tunnel lining construction. Structural Concrete, 17(5), 747-759.

Christodoulides, S. P. (1955) A Two-Dimensional Investigation of the End Anchorage of Post-Tensioned Concrete Members. Structural Engineer, 33(4), $120-133$.

Christodoulides, S. P. (1957) Three-dimensional investigation of the stresses in the end anchorage blocks of a prestressed concrete gantry beam. The Structural Engineer, 35(9), 349-356.

German Tunnelling Committee. (2013) DAUB. Recommendations for the design, production and installation of segmental rings. German Tunnelling Committee.

Eimer, C., Doroskiewicz, R., Michalski, B. and Szule, J. (1966) Anchorage Zone in Pre-stressed Concrete Elements in the Light of Photo-elastic Investigations on Reinforced Models. Archiwum Inzynierii Ladowej, 12, 149.

Francis, O. and Mangione, M. (2012) Developments in joint design for steel fibre reinforced concrete segmental tunnel linings. In: ITA - AITES World Tunnel Congress.

Gupta, P. K. and Khapre, R. N. (2008) A study on development of stresses in anchorage zone using parallel processing. Asian Journal of civil engineering (building and housing), 9(1), $47-59$.

Guyon, Y. (1953) Prestressed Concrete, V. 1, Jointly published by Contractors Record Ltd., London, United Kingdom, and John Wiley \& Sons. Inc., New York, NY, 239.

Guyon, Y. (1972) Limit-state Design of Pre-stressed Concrete Translated by P. Chambon and F. H. Turner. New York: Halsted Press Division, Wiley.

He, Z. Q., \& Liu, Z. (2011) Investigation of bursting forces in anchorage zones: compression-dispersion models and unified design equation. Journal of Bridge Engineering, 16(6), 820-827. 
Hengprathanee, S. (2004) Linear and Nonlinear Finite Element Analyses of Anchorage Zones in Post-Tensioned Concrete Structures, Ph.D. Thesis, Virginia Tech.

Ibell, T. J., \& Burgoyne, C. J. (1992) Behaviour of prestressed concrete end blocks. In Engineering mechanics: proceedings of the ninth conference (p. 135). Amer Society of Civil Engineers.

Iyengar, K. S. R. (1962) Two-dimensional theories of anchorage zone stresses in post-tensioned prestressed beams. In Journal Proceedings, Vol. 59, No. 10, 1443-1466.

Leonhardt, F. (1964) Prestressed concrete: Design and construction. W. Ernst.

Liao, L., De la Fuente, A., Cavalaro, S., Aguado, A., \& Carbonari, G. (2015) Experimental and analytical study of concrete blocks subjected to concentrated loads with an application to TBM-constructed tunnels. Tunnelling and Underground Space Technology, 49, 295-306.

Magnel, G. (1949) Design of the ends of prestressed concrete beams. Concrete and Constructional Engineering, 44(5), 141148.

Moccichino, M., Romualdi, P., Perruzza, P., Meda, A. and Rinaldi, Z. (2010) Experimental Tests on Tunnel Precast Segmental Lining with Fiber Reinforced Concrete. In: World Tunnel Congress (WTC). Vancouver, Canada.

Morsch, E. (1922) Reinforced Concrete Construction - Theory and Application (Der Eisenbetonbau-Seine Theorie und Anwendund). 1. Stuttgart, 112 pp. 5th Edition.

Morsch, E. (1924) Uber die Berechnung der Ge1enkquader. Beton und Eisen, 12, $156-161$.

Olubanwo, A.O., Karadelis, J.N. and Abbey, S.J. (2017) 'Evaluation of Equivalent Delamination Driving Coefficient in Bonded Concrete Overlays: International Journal of Civil Engineering and Technology 8(5) pp. 1436 - 1444.

Olubanwo, A. O., Karadelis, J.N., Saidani, M., Khorami, M. and Abbey, S.J. (2018) 'Investigation of intrinsic de-bonding in bonded concrete overlays: Material characterisation and numerical Study' Engineering Solid Mechanics 6(2) pp. $155-174$.

Okada, K. and Fujii, M. (1964) Some Considerations on Stress Concentration in the Notched Anchorage Zone of Post-Tensioned Concrete Members. Japanese Prestressed Concrete Engineering Association (JPCEA) Journal, 6(6), 32 - 39.

Sargious, M. (1960) Beitrag zur Ermittlung der Hauptzugspannungen am Endauflager vorgespannter Betonbalken, Ph.D. thesis, University of Stuttgart.

Sarles Jr, D., \& Itani, R. Y. (1984) Effect of End Blocks on Anchorage Zone Stresses in Prestressed Concrete Girders. Journal Prestressed Concrete Institute, 29(6), 100-114.

Schnütgen B. Design of precast steel fiber reinforced tunnel elements. Proceedings of the RILEM TC 162-TDF Workshop, Test and design methods for steel fiber reinforced concrete- background and experiences, Bochum, Germany, 2003, pp.145-152.

Sievers, H. (1952) Die Berechnung von Auf1ager-banken und Auf1agerquadern von Bruckenpfei1ern.Der Bauingenieur, 27(6), $209-213$.

Stone, W. C., \& Breen, J. E. (1981) Analysis of post-tensioned girder anchorage zones. NASA STI/Recon Technical Report N, 82 .

Tesar, V. (1932) Dètermination expèrimentale des tensions dans les extrèmitès des pièces prismatiques munies d'une semiarticulation. A. IPC Mémoires, 1.

Tiberti, G., Conforti, A., and Plizzari, G.A. (2015), Precast segments under TBM hydraulic jacks: Experimental investigation on the local splitting behaviour, Tunnelling and Underground Space Technology, 50, pp. 438-450.

Williams, A. (1982) Radial Joints for Precast Segmental Tunnel Linings. TECHNICAL REPORT, 522, ISSN: 0528-3701, (522).

Yettram, A.L. and Robbins, K. (1969) Anchorage zone stresses in axially post-tensioned members of uniform rectangular section. Magazine of Concrete Research, 21(67), 103-112.

Yettram, A.L. and Robbins, K. (1970) Anchorage zone stresses in post-tensioned uniform members with eccentric and multiple anchorages. Magazine of Concrete Research, 22(73), 209-218.

Zhou, L.Y., Liu, Z. and He, Z.Q. (2015) Further investigation of transverse stresses and bursting forces in post-tensioned anchorage zones. Structural ConcreSte, 16(1), 84-92. 